\title{
Informes
}

\section{Carmen A. Miró y la demografía latinoamericana}

\author{
Dídimo Castillo Fernández*
}

Autoridades de El Colegio de México aquí presentes, miembros de la mesa, profesores, alumnos, amigas y amigos:

Agradezco a la doctora Silvia Giorguli la oportunidad de dirigir estas palabras sobre la trayectoria intelectual de una gran mujer, panameña y latinoamericana.

No soy el más indicado para referirme a la amplia trayectoria de la doctora Carmen A. Miró; mi cercanía a ella quizá me haga perder mucho de su horizonte personal e intelectual, que muchos de los aquí presentes conocen mejor que yo. Cualquier intento de caracterización y síntesis de su trayectoria es casi una misión imposible; sin embargo, intentaré destacar algunos aspectos de su vida y obra que considero oportuno compartir.

Carmen Miró nació en la ciudad de Panamá el 19 de abril de 1919, exactamente en el entorno generado por el final de la Primera Guerra Mundial. Es hija del poeta Ricardo Miró, el escritor más destacado y reconocido de la literatura panameña. Desde muy pequeña se nutrió de ese ambiente intelectual y cultural, que tendría como base y referente a lo largo de su vida.

Incursionó en la vida pública desde muy temprano. Siendo muy joven, ejerció su primer empleo en una oficina de la presidencia de la República. Con apenas 27 años, en 1946, fue directora del Departamento de Estadística y Censo de la Contraloría General de la República de Panamá, cargo que

* Profesor investigador de la Universidad Autónoma del Estado de México, Facultad de Ciencias Políticas y Sociales. Correos electrónicos: didimo99@prodigy.net.mx y didmocasti 1lofernandez@gmail.com

Nota del editor: Palabras pronunciadas en la ceremonia de entrega del Premio Daniel Cosío Villegas 2016 a la doctora Carmen A. Miró, otorgado por El Colegio de México y la Fundación Colmex en reconocimiento a su extraordinaria trayectoria en las ciencias sociales, la demografía latinoamericana, el pensamiento sobre la población y el desarrollo, y por su papel como animadora y forjadora de instituciones. El Colegio de México, A.C., jueves 16 de febrero de 2017. 
ejerció por diez años. En ese país se reconoce su desempeño en dicha institución, en la que realizó transformaciones importantes, tanto que, por mucho tiempo, Panamá fue reconocido como uno de los países de la región con estadísticas oficiales más completas y confiables. Eso ha cambiado un poco.

De ahí salió en 1957, invitada por Naciones Unidas para asumir la dirección del recién instituido Centro de Estudios Latinoamericanos de Demografía (Celade), al que dirigió por más de veinte años.

Conocí a Carmen, como muchos, trabajando, precisamente cuando, de vuelta a Panamá (habiendo pasado por El Colegio de México), ella asumía la Secretaría Ejecutiva del Centro de Estudios Latinoamericanos (CELA) "Justo Arosemena", del cual sigue siendo miembro activo de su Consejo Directivo. Era yo estudiante (principiante) de la carrera de Sociología y laboraba en dicha institución como encargado del Centro de Documentación.

Como seguramente les pasó a muchos, mi primera impresión fue la de conocer a una mujer de carácter duro, impresión que rápidamente fui cambiando, en la medida que descubría a la verdadera Carmen: una mujer sensible, generosa, siempre solidaria, siempre deseosa de apoyar y servir a los demás.

En términos muy generales, académicamente la definiría como una mujer visionaria y comprometida, forjadora de grandes proyectos institucionales y académicos, dentro y fuera del país. Algo que cabe destacar es que fue (y es) una fiel defensora de la educación pública, a la que perteneció y se entregó, convencida del papel de la educación en las transformaciones de la sociedad.

No sólo ejerció la docencia en la Universidad de Panamá. En el marco del Celade, a lo largo de su gestión como directora, también fue docente en los cursos de especialización y posgrado que ofrecía la institución. Podríamos considerarla formadora de importantes generaciones de demógrafos en América Latina.

Cabe decir que dos de los demógrafos más destacados, pioneros de la demografía en México, los profesores Gustavo Cabrera (exdirector del Centro de Estudios Demográficos y de Desarrollo Urbano, CEDDU, ahora Centro de Estudios Demográficos, Urbanos y Ambientales, CEDUA) y el profesor Raúl Benítez Zenteno (exdirector e investigador del Instituto de Investigaciones Sociales de la Universidad Nacional Autónoma de México) fueron sus alumnos. En sus pláticas, ambos recordaban mucho y de forma muy amena esa experiencia en Celade.

Tuvo mucha fe en la educación pública puesta al servicio de los jóvenes. Recuerdo mucho esta frase, que le escuché varias veces: "Es preferible un alumno reprobado en la escuela que un delincuente en la calle". Decía tam- 
bién: "El que menos aprende, aprende algo: aprende a ser mejor persona, mejor ciudadano".

Fue, por muchos años, una maestra en el sentido pleno, pero sobre todo, una gran investigadora. Asumió y entendió la demografía no como una disciplina cerrada, aparte de las demás ciencias sociales, sino como parte del sistema complejo de las ciencias humanas y sociales, que colocaba al individuo en el centro de sus preocupaciones. Su concepción interdisciplinaria de la investigación se hace patente en sus planteamientos y en sus investigaciones.

Desde el inicio de su carrera sostuvo que "no había problemas de población", sino "población con problemas". Esto, que no pretendía ser un postulado epistemológico, tampoco era una simple constatación empírica, sino un posicionamiento teórico de enormes consecuencias metodológicas. Lo que Carmen quiere decir es que no hay problemas de población per se, y estrictamente demográficos, sino que implican diversos ámbitos problemáticos a la vez. Ahí estaba la interdisciplina que ella ha reclamado.

Carmen fue impulsora de lo que podríamos llamar la "demografía crítica latinoamericana". Toda su obra está marcada por la confrontación de ideas y crítica al sistema de exclusión social imperante. Fue (y es) crítica en todo el sentido de la palabra: crítica en la concepción, crítica en la solución; crítica en la academia, crítica en la política. Siendo sincero, no he conocido a alguien más crítico en la academia que Carmen.

Concibió y asumió la investigación no como un fin en sí mismo, sino como un medio a través del cual ofrecer pautas para la acción; de allí su empeño por los estudios de las políticas públicas y de la política de población, preocupación que ha estado presente a lo largo de su obra.

Se podría decir que marcó toda una época de desarrollo de los estudios de la población en América Latina. Vivió el largo periodo de incipiente y avanzada industrialización, iniciado con posterioridad a la Segunda Guerra Mundial, con todas las contradicciones generadas: de crecimiento de la pobreza y la marginación, y el corto periodo de rápido crecimiento demográfico en las décadas de 1960 y 1970.

Enfrentó y rebatió las ideas neomalthusianas de la época, las más ortodoxas, que asociaban la pobreza con el rápido crecimiento poblacional, pero también las concepciones más renovadas que asumían que la caída de la fecundidad a tasas o niveles de reemplazo (por sí sola) tendría un efecto sobre el desarrollo económico. Carmen lo puso en duda; reconoció cierto efecto, pero limitado, toda vez que enfatizó en el cambio de modelo económico.

En términos figurados, podríamos decir que vivió todo el periodo de la transición demográfica; pero no sólo fue testigo de ella, sino que incidió 
críticamente en su desarrollo desde las instancias académicas que dirigió y también desde sus investigaciones.

El contexto en el que se desarrolló fue muy rico en la reflexión y el debate crítico. Paralelo a la creación y desarrollo del Celade (1957), fueron también los tiempos de otros desarrollos institucionales, como la Asociación Latinoamericana de Sociología (ALAS) (1950), la Facultad Latinoamericana de Ciencias Sociales (Flacso) (1957, justo en el mismo año de creación de Celade), y el Consejo Latinoamericano de Ciencias Sociales (Clacso) (1967, diez años después).

Fue una época de grandes debates sobre la modernización (teoría para la que el crecimiento demográfico representaba una "anomalía"), sobre el desarrollo, la dependencia, la marginalidad, entre otros. En el ámbito político, también fueron tiempos de mucha movilización social y de construcción de utopías. Carmen no estuvo al margen de ello, tuvo siempre una participación política activa.

Sus antecedentes, en ese sentido, se remontan a lo que en Panamá se denominó el Frente Patriótico de la Juventud, un movimiento social progresista de finales de la década de 1940 que, entre otras demandas, rechazaba la presencia norteamericana en la llamada Zona del Canal y en otras áreas del país.

Los amigos(as) chilenos(a) y latinoamericanos recuerdan con mucho afecto y agradecimiento el apoyo que les ofreció Carmen desde el Celade, durante el golpe de Estado al presidente Salvador Allende y la represión de la que muchos fueron objeto.

En Panamá destacó su participación como candidata a la vicepresidencia de la República, en nómina con el doctor Renán Esquivel, un salubrista, médico progresista muy reconocido por sus conceptos y visión social de la salud, en lo que se llamó el Frente Electoral Pueblo Unido (Frepu), en las elecciones de 1984; las primeras en las que participé, y en las que, como suele pasar en muchos de nuestros países con los proyectos alternativos, no tuvimos éxito.

Carmen es una de las académicas más querida, conocida y reconocida por sus contribuciones a la investigación demográfica en América Latina. El desarrollo de la demografía en dicha región está indefectiblemente ligado a su persona y su obra.

Su producción y trayectoria académica son vastas, pero sobre todo muy significativas en el planteamiento y replanteamiento de problemas. Su obra está contenida en varios libros y, mucho de ella, en artículos en revistas de investigación científica.

Parte de esa producción está recogida en el libro Población y desarrollo, en el que la doctora Brígida García y su servidor seleccionamos algunos de 
sus trabajos; fue editado originalmente en la colección Pensamiento Crítico Latinoamericano, por el Consejo Latinoamericano de Ciencias Sociales (Clacso) y la editorial Siglo de Hombre (Colombia); y la segunda edición, integrada a la colección Antología del Pensamiento Social Latinoamericano y Caribeño, fue editada por Clacso y Siglo XXI Editores.

Carmen fue una gran gestora y promotora de la investigación y el conocimiento científico: además de la dirección de Estadística y Censo (en Panamá), de Celade (en Chile), y del Centro de Estudios Latinoamericanos "Justo Arosemena" (ya mencionado), en Panamá también dirigió el Instituto de Estudios Nacionales (IDEN) de la Universidad de Panamá, del que fue su primera directora y al que con toda su experiencia pudo enrumbar durante sus primeros años.

Su trabajo le ha valido muchísimos reconocimientos, entre otros: el Doctorado Honoris Causa de la Universidad de La Habana, Cuba; el Doctorado Honoris Causa de la Universidad de Córdoba, Argentina; el Doctorado Honoris Causa por la Facultad Latinoamericana de Ciencias Sociales, y el Premio Mundial de Población, otorgado por Naciones Unidas, en 1984.

El Premio "Daniel Cosío Villegas", que hoy otorga El Colegio de México, es sin duda uno de los que más le hubiera emocionado recibir personalmente. Estoy seguro y cierto que nada le hubiera gustado más que estar aquí, pero su salud no se lo permite.

Gracias doctora Silvia Giorguli, gracias doctora Brígida García -siempre muy querida y recordada por Carmen-, autoridades de El Colegio de México, gracias, gracias amigos y amigas de Carmen. ¡Muchas gracias! 
